\title{
DETERMINATION OF TRAFFIC FLOWS PARAMETERS ON THE MANAGEMENT NETWORK
}

\section{Nataliia Semchenko ${ }^{1}$}

DOI: https://doi.org/10.30525/978-9934-26-001-8-2-10

Abstract. The work is devoted to the actual problem of determining the parameters of dense traffic flows on the road cities network, which can be used when introducing automated traffic control systems. The subject of the study is to determine the parameters of traffic flows in the central part of the city. The purpose of the work is to develop methods for determining the parameters of traffic flows of the street and road network on the basis of empirical and analytical modeling to reduce the number of peripheral measuring devices in the automated traffic control system. Methodology. In the given thesis there was solved the applied scientific problem of shortterm operational forecasting of the traffic flow intensity on the transport network using the empirical-analytical approach, in which the measurement of traffic flow parameters at the entrances to the area of traffic flow management is carried out by transport detectors, internal local objects are determined by modeling. The proposed model is based on the determination of intensities at approaches to stop lines of internal crossroads of the management area using recurrent sequences. Experimental researches of traffic flows on the network and on the crossings were carried out using video filming during periods of maximum load. A comparative analysis of the simulation results with the experimental data showed that the relative error on a network with an area of 50-60 hectares does not exceed 3\%, which indicates the adequacy of the model and the possibility of using it for management tasks. Practical implications. Implementation of the empirical-analytical method in automated traffic management systems will make it possible to reduce the number of detectors by $43-46 \%$ depending on the area of traffic management and obtain a sufficient economic effect. The regularities of the movement of dense traffic flows of high specific

\footnotetext{
${ }^{1}$ Candidate of Technical Sciences,

Associate Professor at Department of Traffic Management and Road Safety,

Kharkiv National Automobile and Highway University, Ukraine
}

(C) Nataliia Semchenko 
intensity on short hauls, typical for the central parts of cities, have been investigated. Value/originality. According to experimental results there were obtained approximating models of parameters of the logarithmic normal probabilistic law of time intervals distribution in dense traffic flows, the specific intensity of which exceeds $600 \mathrm{vph}$; the changes in basic characteristics of the vehicles group in the traffic flow when driving through the road crossing taking into account its intensity and the distance from the group forming object are determined.

\section{Introduction}

Problems of traffic safety and efficiency of transport systems are extremely important today, which requires effective measures to improve traffic management. This is especially true of the central parts of the largest and most significant cities, the street and road network of which operates with overvoltage, as evidenced by the systematically occurring stop-and-go and congestion situations, the growing number of road accidents.

Situations on the street and road network of such cities are changing quite rapidly, and the size of the control object is so large that dispatching it in manual control mode is not possible. This led to the introduction of automated traffic control systems. At the same time, the development of digital technologies and technical means of obtaining operational information and implementation of the adopted decisions creates preconditions for further development of the introduction of automated traffic control systems.

The functional capabilities of the automated traffic control systems operating in Ukraine are reduced to the implementation of rigid multiprogram coordinated management of traffic and pedestrian flows on separate highways. Automation of information collection is theoretically possible, but practically not used due to the small number of peripheral sensors and their low reliability, which is caused by poor road surface and outdated technology of their installation. Automated methods for calculating control parameters are used to a very limited extent due to the lack of proper software. Another reason for insufficient implementation of modern traffic management systems in Ukraine is their high cost.

In addition, due to a significant increase in the number of cars over the last decade, the capacity of the street and road network has been almost 
completely exhausted, which complicates traffic conditions and requires improved performance of the existing network. Increasing the capacity of the street and road network requires a detailed study of the characteristics of high-density transport flows.

The aim of the work is to develop methods for determining the parameters of traffic flows of the street and road network on the basis of empirical and analytical modeling to reduce the number of peripheral measuring devices in the automated traffic control systems.

The scientific novelty of the obtained results is that the possibility of using empirical-analytical modeling of traffic flow parameters for use in automated traffic control systems is substantiated: the connection of parameters of logarithmically normal distribution of time dynamic size of vehicles in dense traffic flows with specific intensity exceeding is established and formalized. $600 \mathrm{vph}$, and the distance from the groupforming object, which allows the use of modeling in determining the control modes; methods of short-term operative determination of traffic flow intensity by analytical modeling of traffic intensity within the network of the control district on the basis of the information received from transport detectors at its main entrances were further developed.

The practical significance of the obtained results is to develop a method of empirical and analytical determination of the intensity of traffic flows in the network of the central part of cities for use in automated traffic control systems.

The approaches used make it possible to determine traffic flows in the city network using only data from traffic surveys at its entrances, which reduces the number of transport detectors to obtain source information, reduce the cost of implementing automated traffic control systems and get a significant economic effect that depends on the area.

The developed models can be used to study the traffic process, assess the level of loading of sections of the transport network for further use during the development of projects for the traffic management and reconstruction of urban roads. The proposed model of distribution of traffic flows on the network and the model of distribution of time dynamic size of vehicles can be applied in control algorithms of automated traffic control systems. 


\section{Analysis of traffic control systems in cities}

Principles and structure of traffic management are stated in scientific works of experts: Yu.O. Kremenets, M.O. Brailovsky, E.M. Lobanov, V.V. Silyanov, M.P. Pechersky, O.G. Romanov, V.I. Konoplyanka, V.F. Babkova, O.P. Vasilieva, V.T. Kapitanova, O.Yu. Mikhailova, B.M. Chetverukhina, D.S. Samoilova, V.I. Yeresova, V.P. Polishchuk, E.O. Reitsen, G.I. Klinkovstein, O.O. Lobashov, L.S. Abramova, H. Inose, D.R. Drew, F. Heit and many other scientists [1, c. 294].

All traffic control methods operate in space (local and network) and in time (off-line and on-line methods) [2, c. 85; 3, c. 7; 4, c. 26; 5, c. 56]. Offline (autonomous) methods include almost all methods of forced control (rigid) of traffic and pedestrian flows. On-line methods (real time) involve the use of manual control at the crossroads and numerous automated control algorithms based on receiving information from traffic flow sensors. Depending on the combination of these criteria, each method of automated traffic control belongs to one of the classes: local rigid control algorithms; network rigid control algorithms; local adaptive control algorithms; network adaptive control algorithms.

Among the methods of traffic control in conditions of high traffic intensities and a high probability of congestion situations, the most effective are network adaptive methods used in the most common traffic control systems in cities. SCOOT $[2$, c. $101 ; 6$, c. $3 ; 7$, c. $46 ; 8$, c. 17] and UTOPIA [7, c. 46; 8, c. 17], which are a further development of the method of calculating rigid network coordination plans TRANSYT [2, c. 90; 9, c. 2; 10, c. 276]. Existing adaptive automated traffic control systems provide transport flows management on the basis of real-time source data from metering points. This approach requires the use of transport detectors at each local control facility and, consequently, significant costs for the implementation of automated traffic control systems. The cost of transport detectors, taking into account communications, ranges from $32 \%$ for a section with one lane in each direction to $48 \%$ for a section with three lanes in each direction [11, p. 41-42] in relation to the cost of equipping the crossroads where measurement of data by transport detectors [8, p. 17].

Analytical methods for determining the patterns of traffic flows on the street and road network are based on modeling the traffic flow. Depending on the outlined task, the term for determining the intensity of traffic flows 
on the network over time varies from long-term to short-term [8, p. 24]. In the case of using simulation data for the operation of automated traffic control systems, this period should not exceed the time during which the absolute values of intensity do not have time to change significantly in the network of the management area. This time, in contrast to the short-term, in the work is defined as short-term operational.

The analysis of modern methods of modeling the distribution of traffic flows over the network proved the possibility of developing analytical methods for short-term operational determination of traffic intensity on network elements, which will significantly reduce the number of transport detectors.

As a result of the analysis of existing models of vehicle traffic on the cross-sections of the transport network, it was determined that they take into account the properties of traffic flow only at low and medium specific traffic $[12$, p. 8], not exceeding $600 \mathrm{vph}$. Since the average value of the specific intensity on urban highways today exceeds $600 \mathrm{vph}$, the establishment of laws of distribution of time intervals between vehicles, the formation of groups of vehicles and their deformation in the traffic flow of this intensity require experimental studies.

\section{Empirical and analytical modeling of traffic flow intensity on the network}

The traffic control area (management area) is a set of road sections and crossroads located in the area of traffic lights and controlled signs covered by auto-mated traffic control systems [13, p. 2] (Figure 1).

In transport planning to characterize transport pairs $(i, j)$ distinguish between the concepts of departure-arrival and origin-attraction of travel. Different pairs of trips $(i, j)$ are formed by superimposing on the transport network two spatial structures: sets of points of occurrence of trips - sources and set of points of end of trips - drains. The degree of aggregation of the transport network should correspond to the demand for transport services, depending on what is meant by the vertices of the network structure $\mathrm{i}, \mathrm{j}$ : regions, transport areas, transport stops, terminals, etc.

During the development of the model it is accepted that:

- as the vertices of the network structure it is proposed to consider the stop lines of the crossroads; 


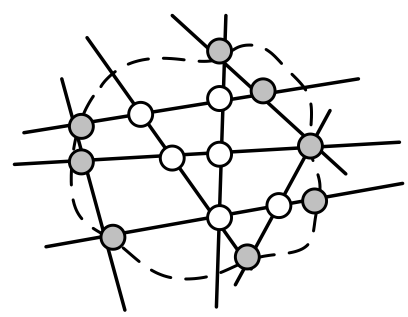

- - border of the management area;

- crossroads;

- point of information collection on traffic flows;

- road section.

Figure 1. Schematic location of information collection points on the transport network of the city

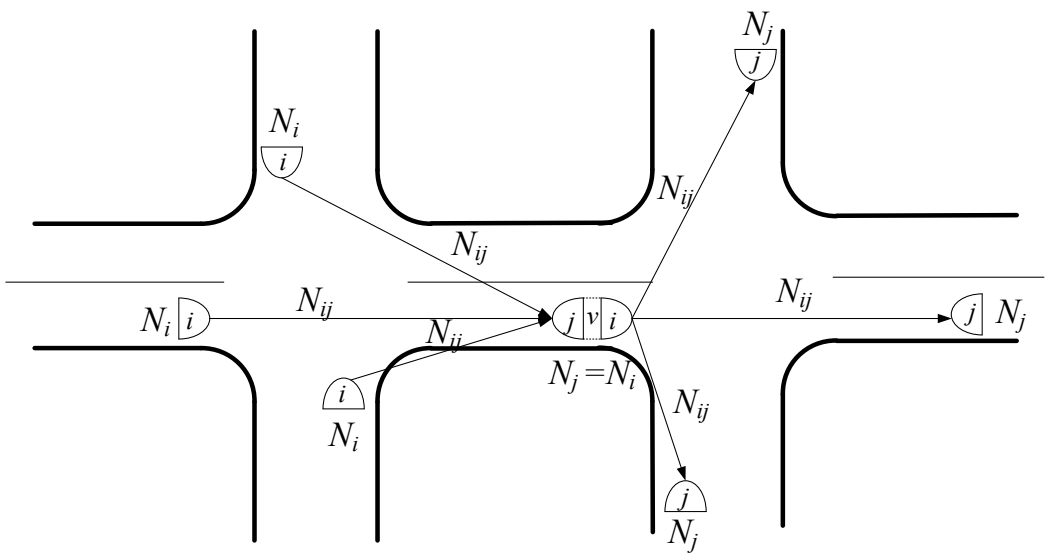

- the stop line of the intersection from which the vehicles depart;

-the stop line of the intersection to which vehicles arrive;

(v) -stop line $v$ of the intersection to which vehicles arrive and depart;

$N_{i}$ - volume of departure from the stop line $i$ to all others, vph.;

$N_{j}$ - volume of arrival to the stop line $j$, vph.;

$N_{i j}$ - intensity of traffic flow from the stop line $i$ to the stop line $j$, vph.;

$i$ - stop line number, if it is considered by departure.

Figure 2. Schemes of transport connections by departures and arrivals 
- the number of stop lines preceding the one under consideration does not exceed three. Any crossroads with more than four roads can be reduced to an crossroads with no more than four roads by introducing conditional stop lines.

The volume of transport flow traffic in the crossroads stop line can be considered either by departures or by arrivals (Figure 2), but both of these options are equivalent, since the number of departures in the stop lines corresponds to the number of arrivals.

Considering the stop line $\mathrm{v}$ of the crossroads as an object of origin and absorption of correspondence, the condition is fulfilled

$$
N_{i}=N_{j},
$$

where $\mathrm{Ni}$ is the intensity of transport flow sent from the stop line, vph; $N_{j}$ - intensity of transport flow arriving at the stop line, vph.

Given the requirements for modeling the distribution of transport flow on the network, the method of linking the transport model to the street and road network using a graph model was chosen. The transport network is presented in the form of an oriented graph $G(V, E)$, where $V$ is the set of vertices, $E$ is the set of network arcs. Each vertex reflects the stop line of the crossroads.

Each arc corresponds to the actual section of the road between the stop lines of crossroads. The direction of the arc corresponds to the direction of movement of vehicles from the stop line - straight, right and left. The rules of bypassing the graph are determined by the existing traffic management. Therefore, the street and road network is given in the form of an oriented graph, which includes a detailed representation of crossroads and solutions in the form of vertices and arcs. Each oriented arc has qualitative characteristics (number of lanes in each direction, type of coverage, type of management, etc.).

During research of flow-forming factors in the set of vertices $\mathrm{V}$ there are two subsets: the first $S \subseteq V$ contains points that generate transport flow (sources); the second $D \subseteq V$ contains points that absorb transport flow (drains). On the other hand, the set of vertices $V=\left\{v_{t}, t=\overline{1, m}\right\}$ can be represented as a union of three sets: the first $V^{\text {in }}$ contains points representing only the sources, $V^{i n}=\left\{v_{t}^{i n}, t=\overline{1, n}\right\}$; the second $V^{\text {int }}$ contains items representing both sources and drains at the same time, 
$V^{\text {int }}=\left\{v_{t}^{\text {int }}, t=\overline{n+1, r}\right\} ;$ the third $V^{\text {out }}$ contains items representing only drains, $V^{\text {out }}=\left\{v_{t}^{\text {out }}, t=\overline{r+1, m}\right\}$. At the same time, $S=V^{\text {in }} \cup V^{\text {int }}$, $D=V^{\text {out }} \cup V^{\text {int }}$. Regarding the task of transport flow modeling, only the sources are the stop lines at the entrances to the management area; only drains are conditional stop lines at the exit from the management area, and sources and drains are at the same time all internal stop lines of the management area. The set of all flow-forming pairs is given in the form of a Cartesian product:

$$
W=\{w=(i, j): i \in S, j \in D, i<j\} .
$$

Each $\operatorname{arc} e_{t} \in E$, which connects adjacent stop lines (source and drain), corresponds to a quantitative characteristic - the transport flow intensity $N_{e_{t}}$, which has fixed values.

The path $l$ (route) in the network $G$, which connects any vertices $i$ and $j$, is a sequence of $\operatorname{arcs} e_{1}=\left(i=v_{1} \rightarrow v_{2}\right), e_{2}=\left(v_{2} \rightarrow v_{3}\right), \ldots, e_{s}=\left(v_{s} \rightarrow v_{s+1}=j\right)$, where $e_{t \in} E$ for all $t=\overline{1, s}$. There are no loops and cycles in the routes, the routes are simple. The set of alternative routes, following which on each arc between a pair of vertices $w=(i, j) \in W$ is determined by the intensity of the transport flow arising from the source $i$, reaches the runoff $j$ is denoted by $L_{w}$. Then the set of all paths in the network $G: L=\bigcup_{w \in W} L_{w}$.

Transport flow at the crossroads $k$ is characterized by:

- the topology of the graph corresponding node projection: $V_{k}$ - the set of crossroads stop lines $k$, which quantitatively coincides with the number of approaches to the crossroads, $V_{k}=\left\{v_{k}^{p}, p=\overline{1, P}\right\} ; \quad P \leq 4 ; p$ - the number of the approach to the crossroads; $V^{k} \subset V, V$ - the set of network stop lines, $V=\left\{v_{t}, t=\overline{1, m}\right\} ; m-$ the number of stop lines at the network, taking into account the conditional stop lines at the exit from the management area (non-negative integer); $K$ - the set of crossroads in the management network; $K=\left\{k, k=\overline{1, M_{k}}\right\} ; M_{k}-$ number of crossroads in the network (non-negative integer);

- matrix $F_{k}^{p}=\left(f_{k}^{p}\right)$, where $f_{k}^{p}$ - the value of the share of the flow of vehicles maneuvering at the crossroads $k$ from the stop line $v_{k}^{p}$, obtained on the basis of traffic management data 


$$
f_{k}^{p}= \begin{cases}a_{k}^{p}, & \text { straight from the stop line } v_{k}^{p}, \\ b_{k}^{p}, & \text { to the right of the stop line } v_{k}^{p}, \\ c_{k}^{p}, & \text { to the left of the stop line } v_{k}^{p} .\end{cases}
$$

$0 \leq f_{k}^{p} \leq 1$, and the condition is fulfilled

$$
a_{k}^{p}+b_{k}^{p}+c_{k}^{p}=1 \text {. }
$$

The values of the share of the flow of vehicles performing the corresponding maneuver from the stop lines $i$ are determined by preliminary experimental studies. The turn maneuver at the crossroads is not considered, due to the insignificant probability of its occurrence.

The value of the transport flow intensity on the approach to the stop line $v_{k+1}^{p}$ of the crossroads $k+1$ inside the management area (Figure 3 ) is calculated by the formula

$$
N_{k+1}^{p}=\sum_{v_{k}^{p} \in V_{k}} N_{k}^{p} f_{k}^{p}
$$

where $N_{k+1}^{p}$ - the intensity of transport flow on the approach to the stop line $v_{k+1}^{p}$ of the crossroads $k+1$ under consideration, vph.; $v_{k+1}^{p} \in V_{k+1} ; N_{k}^{p}-$ intensity of transport flow on the approach to the stop line $v_{k}^{p}$ of the previous crossroads $k$, vph; $v_{k}^{p} \in V_{k} ; k$ - the number of the previous crossroads from which the transport flow exits; $v_{k}^{p}$ - number of stop line of crossroads $k$; $v_{k+1}^{p}$ - number of the stop line of the crossroads $k+1 ; p$ - the number of the approach to the crossroads under consideration.

The transport flow intensity $N_{k+s}$ near each stop line is a linear combination of the transport flow intensities $N_{k+s-1}, N_{k+s-2}, \ldots, N_{k}$ of the previous stop lines and, thus, the transport flow intensities near all stop lines form a recurrent sequence, for the elements of which there exists a natural number $s$ and the numbers $a_{1}, a_{2} \ldots a_{\mathrm{s}}$ (real or imaginary, and the finite number $a_{s} \neq 0$ ) and for any member of the sequence there is a unequivocal conformity

$$
N_{k+s}=a_{1} N_{k+s-1}+a_{2} N_{k+s-2}+\ldots+a_{s} N_{k} .
$$

Continuing the iterative process, using relations (6) for the previous stop lines we obtain the value of the intensity of the transport flow $N_{k+1}^{p}$ on the approach to the stop line, using as initial data the values of the intensity of the transport flow $N_{t}^{i n}$, vph., on the approach to the stop lines $v_{t}^{\text {in }} \in V^{i n}$ at the inputs management area 


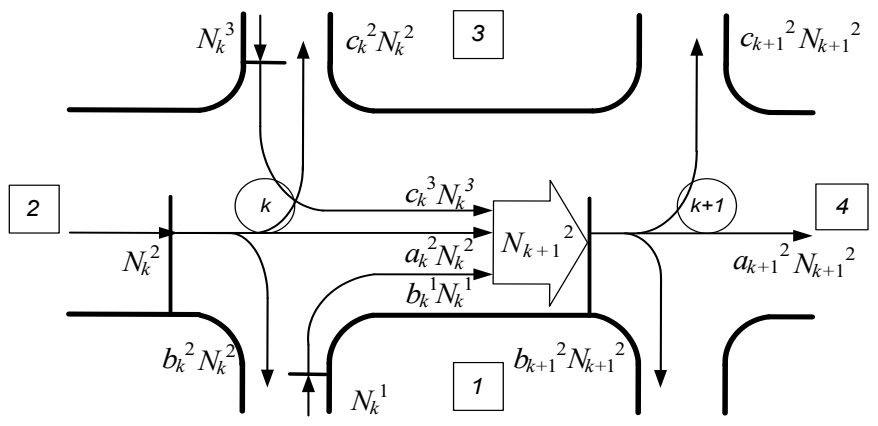

(k) - intersection number;

1 - number of the approach to the intersection;

$a_{k}{ }^{p}, b_{k}{ }^{p}, c_{k}{ }^{p}$ - the proportion of the flow of vehicles maneuvering from the stop line $v_{k}^{p}$ (straight, right, left, respectively);

$N_{k}^{p}$ - the intensity of the arrival of traffic to the stop line $v_{k}^{p}$ intersection $k$;

$a_{k}^{p} N_{k}^{p}, b_{k}^{p} N_{k}^{p}, c_{k}^{p} N_{k}^{p}$ - the intensity of the part of the traffic flow that performs the corresponding maneuver from the stop line $v_{k}^{p}$ intersection $k$;

- the intensity of the arrival of traffic flow to the stop line under consideration.

Figure 3. Model of traffic flow by running from one crossroads to the next

$$
N_{k+1}^{p}=\sum_{v_{t}^{i n} \in V^{i n}}\left(N_{t}^{i n} \sum_{l \in L_{w}} \prod_{v_{k}^{p} \in l} f_{k}^{p}\right),
$$

where $N_{t}^{\text {in }}$ - the transport flow intensity on the approach to the stop line $v_{t}^{\text {in }}$. The iterative process is completed if the condition is met $[14$, p. $71-84$, 15, p. 239]

$$
\left|1-\frac{N_{k, t+1}^{p}}{N_{k, t}^{p}}\right| \leq \varepsilon,
$$

where $N_{k, t}^{p}$ - the intensity of transport flow obtained at the iteration of $t$, vph; $N_{k, t+1}^{p}-$ transport flow intensity obtained at the iteration of $t+1$, vph; $t$ - the iteration number; $\varepsilon$ - the given accuracy of calculation (in work $\varepsilon$ is equal to 0,01 ).

The developed method of determining the intensity of transport flow on approaches to stop lines involves a representation of the system of linear 
equations obtained on the basis of (5) for each stop line of the management network, in matrix form with a finite set of empirical output data on the intensity of transport flow on approaches to stop lines that are inputs to the management network. According to the developed technique the values of intensity of transport flow on approaches to internal stop-lines of a network of the area of management and on exits from it are calculated.

When implementing traffic management measures, including the definition of control regimes in the case of the use of automated traffic control systems, the initial parameters are the characteristics of the transport flow, including the time interval between vehicles in the flow, the size and shape of groups of vehicles. If no detector data are available, this data is determined according to the proposed transport flow model or probabilistic distribution law.

Intervals between cars with increasing intensity are sharply shifted to the range of smaller values, which suggests the subordination of their distribution at the transport flow intensity, exceeding $600 \mathrm{vph}$, logarithmically normal probability law $[16$, p. 178; 17, p. 231]. This assumption is confirmed by experimental studies.

The parameters of the logarithmically normal distribution of the time dynamic dimension in the group of vehicles determine their size and shape. The general form of models of parameters of logarithmically normal distribution of time dynamic size in group of vehicles for movement in dense transport flow by races of the central part of the city is offered. object.

The parameters of the logarithmically normal distribution of the time dynamic dimension in a group of vehicles determine their size and shape. The general form of the logarithmically normal distribution parameters models of the temporal dynamic dimension in a group of vehicles when driving in a dense traffic flow along the routes of the central part of the city is offered, allowing to take into account changes in their properties at different values of intensity and at different distances from the groupforming object.

\section{Empirical determination of transport flow parameters}

Field studies were conducted in Kharkiv using video: on the district network to determine the existing distribution of traffic flows and verify the adequacy of the developed model; on the busiest magistrals to clarify the 
law of distribution of time intervals and to estimate the deformation of the group at high flow intensity.

During the field experiment, observers with video cameras were at the network of a $0.55 \mathrm{~km}^{2}$ part of the Kyiv district of Kharkiv at 27 crossroads. The equipment registered all directions of entry and exit of vehicles on a weekday, from 900 to 1000 hours, simultaneously at all crossroads of the studied network (Figure 4).

As a result of processing of experimental data parameters of transport flow on each approach to each crossroads on the investigated network are received: structure of a transport stream; hourly intensity of vehicles in physical and reduced units with a breakdown into 5-minute and 15-minute intervals; the percentage of flows near the stop lines in the directions.

Experimental studies of the process of transport flow traffic after passing a regulated crossroads were conducted on sections of highways in Kharkiv with a length of 500-600 m on weekdays, in particular on Tuesday, Wednesday, Thursday, from $8^{00}$ to $11^{00}$. The registration of the moments of passing the management border by cars was performed simultaneously at three stationary posts located at the exit from the crossroads and at a distance of $200 \mathrm{~m}$ and $400 \mathrm{~m}$ from it, using video cameras (Figure 5).
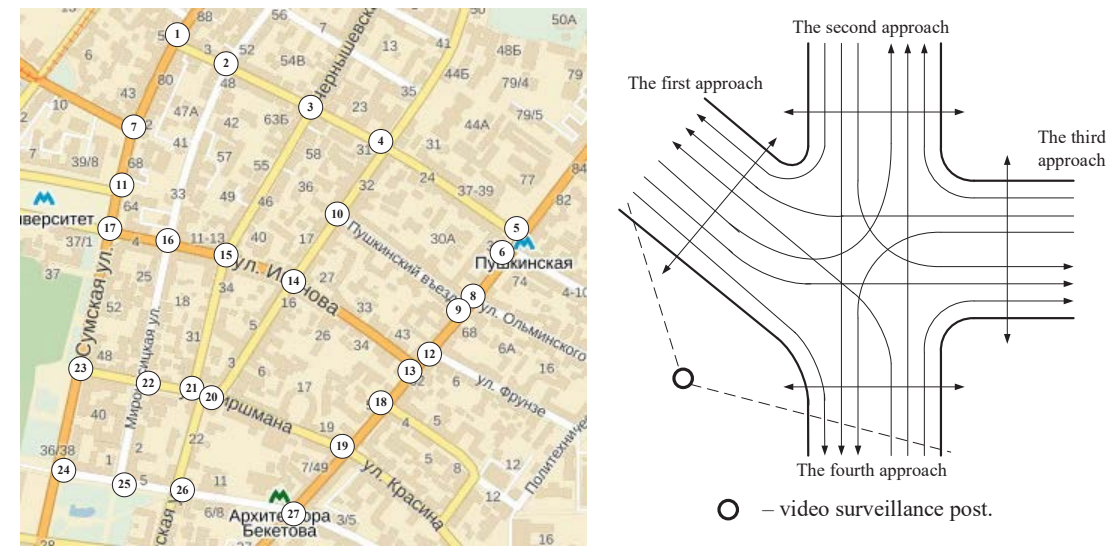

Figure 4. The scheme of the transport network under study with the location of the video surveillance post at the crossroads 


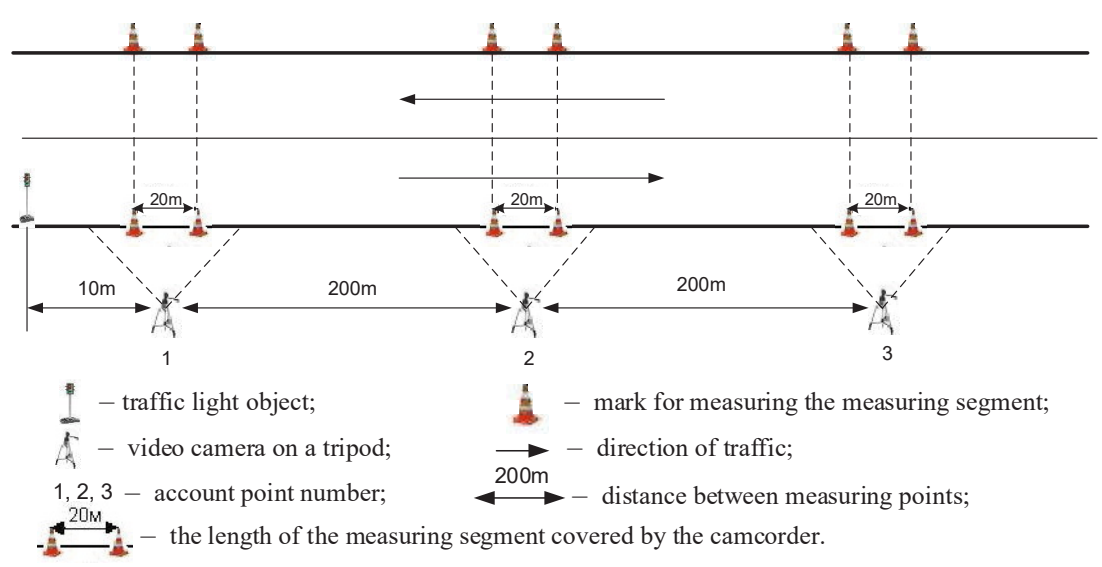

\section{Figure 5. Layout of accounting points on sections of the road transport network}

The obtained video of traffic flows on the city's road network for a predetermined period of time was processed on a computer by dividing into frames with an interval of $\Delta \mathrm{t}=0.04 \mathrm{~s}$ ( 25 frames per second) using the created software "GetIntervalDistribution" [18, p. 15-17]. As a result of video processing, time intervals were obtained at different values of the initial traffic intensity in different lanes.

Various theoretical probability distributions were used to describe the experimental data, which, in addition to the logarithmically normal distribution, were rejected according to the Pearson, Romanovsky and Kolmogorov-Smirnov goodness-of-fit criteria.

Using the nonparametric Mann-Whitney mean comparison criterion, the hypothesis that the value of the time dynamic dimension at the management boundaries is subject to a logarithmically normal distribution regardless of the experiment location and the distance from the controlled crossroads was tested.

During the processing of experimental data, the average values of the time dynamic size in a group of cars at different distances from the regulated crossroads (10 m, $200 \mathrm{~m}, 400 \mathrm{~m})$ and at different specific traffic intensities were also obtained. The non-parametric $H$-criterion of Kraskel-Wallis confirmed that the influence of the distance from the regulated crossroads 

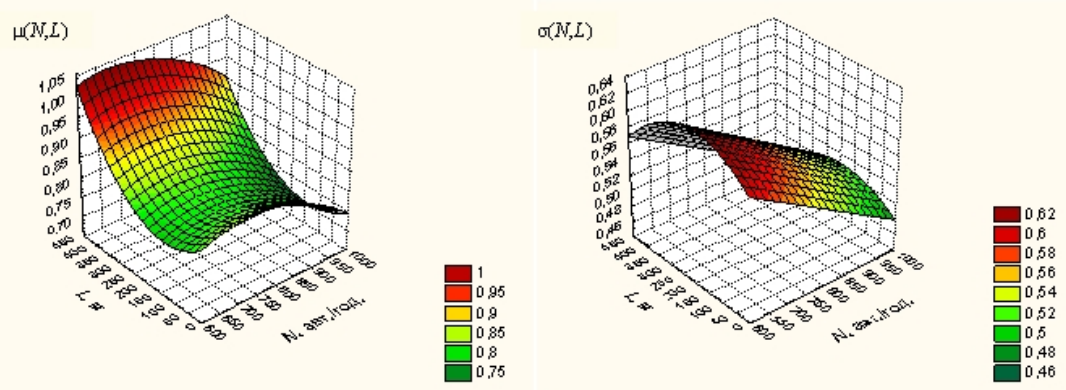

Figure 6. Parameters of the logarithmically normal distribution

and the value of the specific intensity on the value of the time dynamic dimension in the group of vehicles can be considered significant.

Empirical multifactorial dependences are obtained on the basis of onedimensional dependences of the parameters of the lognormal distribution on the parameters of intensity and distance from the group-forming object (Figure 6).

$$
\begin{gathered}
\mu=g(N, L)=1,171 \cdot \mu(N)^{0,992} \cdot \mu(L)^{0,995,}, \\
\sigma=h(N, L)=1,774 \cdot \sigma(N)^{0,991} \cdot \sigma(L)^{0,968,}
\end{gathered}
$$

where $\mu$ - the scale parameter of the logarithmically normal distribution of the values of the time dynamic dimension in the group of vehicles; $\sigma-\mathrm{a}$ parameter of the form of the logarithmically normal distribution of values of the time dynamic dimension in the group of vehicles; $N$ - value of specific traffic intensity, vph.; $L$ - the value of the distance from the group-forming object, $\mathrm{m}$.

The adequacy of the regression model was checked according to the scheme:

- checking the significance of the regression equation;

- checking the statistical significance of the coefficients of the regression equation;

- verification of the prerequisites for the application of the least squares method: the normal distribution and independence of errors, the property of homoskedasticity. 
The results of checking the adequacy of the regression model and analysis of the residuals confirmed that the conditions of applicability of the least squares method are not violated, and the multiple linear regression models are adequate. The numerical experiment determined that the significance level of approximating models of parameters of logarithmically normal distribution of time dynamic dimension did not exceed 0.05 , the calculated value of Fisher's criterion for all models is more than tabular, which confirms the information capacity of the obtained approximating models.

The obtained models of the influence of these factors on the parameters of the logarithmically normal distribution of the time dynamic dimension in a group of vehicles make it possible to determine the characteristics of transport flow motion: mode, median, mathematical expectation, variance, standard deviation, standard error, asymmetry and excess coefficients.

\section{Assessment of the adequacy of the proposed model}

The work performs a comparative analysis of experimental and theoretical data on the parameters of traffic flows in the district network, determined the real distribution of traffic flows in the network and tested the adequacy of the developed model. Theoretical values of traffic intensity were obtained using the experimental-analytical method and Microsoft Excel software.

The comparison of the simulation results on a PC according to the proposed method with the experimental data proves that the absolute error on the arcs of the network varies in the range of $1-58 \mathrm{vph}$, and the relative error does not exceed $10 \%$. The weighted average network error of 50-60 hectares does not exceed 3\%, which confirms the adequacy of the model [15, p. 204].

Since the modeling error on the network with an area of 55 hectares does not exceed $3 \%$, it can be assumed that the area of the empiricalanalytical determination of the intensity of transport flow according to the proposed scheme can be increased. Using correlation analysis, the relationship between the area of the area and the weighted average deviation of the simulated traffic intensity from the actual one was checked. The correlation coefficient and the determination coefficient close to unity prove that the parameters have a very close relationship, and the model obtained by the method of least squares explains almost all the variability of the corresponding variables. The results of checking the adequacy of the 


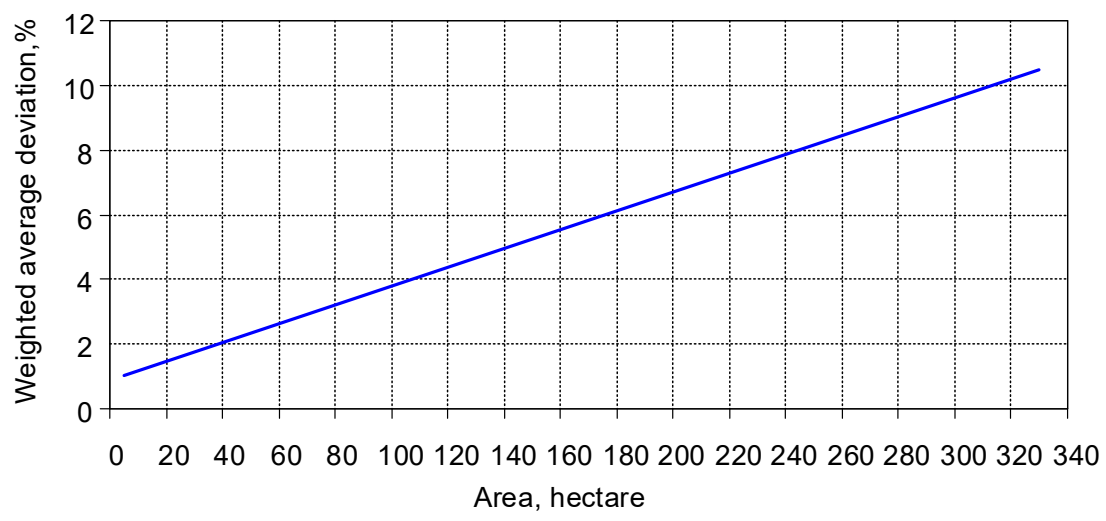

Figure 7. Dependence of the weighted average deviation of the simulated intensity of traffic flows on the area

regression model and analysis of the residues confirmed that the conditions of applicability of the least squares method are not violated, and the linear regression model is adequate. The adjusted dependence has the form

$$
\delta N_{\text {network }}=0,8831+0,0291 \cdot S,
$$

where $\delta N_{\text {network }}$ - weighted average deviation of the simulated traffic intensity from the actual one; $\mathrm{S}$ - area of the district, hectare.

According to the obtained dependence of the regression model, the weighted average deviations of the actual values of the intensity from the simulated ones are calculated (Figure 7).

The modeling error according to the established regression dependence does not exceed $10 \%$ for the area of the management area of 310 hectares.

\section{Assessment of the economic feasibility of its practical implementation}

The economic effect of the introduction of the empirical-analytical model for calculating the parameters of traffic flows in the automated traffic control systems can be obtained by removing transport detectors from a number of local objects in the middle of the control area and replacing them with modeling data. 
The analysis shows that the number of local facilities in the transport areas of the central part of the city, which require traffic light equipment, is $60-70 \%$ of the total number of crossroads. The number of stop lines exceeds the total number of crossroads by 2.5-3.0 (on average 2.7) times, taking into account the planning characteristics of crossroads and the existing traffic management.

Only transport detectors located in the middle of the management area need to be removed and replaced with simulation data. Analysis of the number of crossroads in the central part of the city depending on the area of the district proved that their number, as well as the number of stop lines and, accordingly, these detectors, is subject to the linear law.

The limits of the values of the total cost of removed detectors and the economic effect of installing detection systems are calculated from the conditions that the number of detectors in the lane -1 , the number of

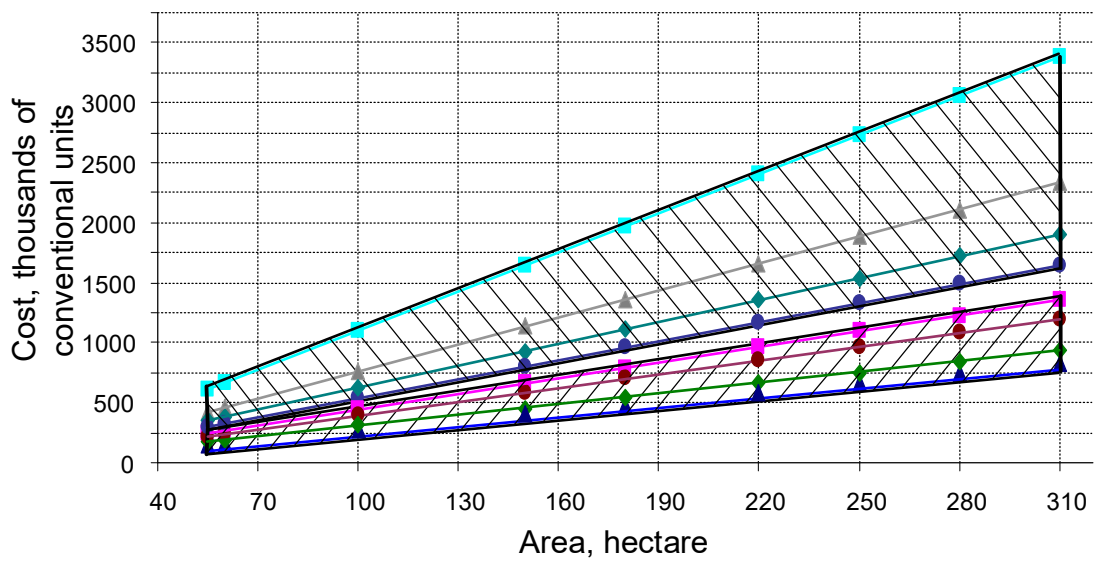

$\boldsymbol{\Delta}$ - the total cost of removed detectors such as inductive frame;

- total cost of seized radar detectors;

- the total cost of seized detectors such as video detector;

- the total cost of seized detectors such as acoustic detector;

- savings in the installation of detection systems with detectors such as video detector;

- - savings when installing detection systems with detectors such as acoustic detector;

$\Delta$ - savings in the installation of detection systems with detectors such as inductive frame;

- savings when installing detection systems with radar detectors.

Figure 8. Change in the total cost of seized transport detectors and installation costs depending on their type and area 
lanes on the approach to the crossroads -2 , the number of detectors on the approach -2 , the number of approaches -4 , the number of detectors at the crossroads -8 . For other conditions due to the introduction of a certain automated traffic control systems, which has its own level of density of detectors, as well as the cost of other types of detectors, the economic effect of the introduction of automated traffic control systems may vary.

Given that the cost of one detector is from 4800 USD (for detector type - inductive frame) up to 7900 USD (for the type of detector - radar) [11, p. 41-42], the total cost of seized detectors on the management area of 55 hectares will be 163200 - 268600 USD The minimum savings, taking into account the installation of detection systems for the same area is 326400-669120 USD In the case of expansion of the management area, the economic effect increases (Figure 8).

Additional savings are possible by reducing the cost of installing detection systems that include the cost of establishing communication links. However, communication between local objects and the central management place is necessary in the case of empirical and analytical modeling.

\section{Conclusions}

1. The analysis of traffic management systems in cities has shown that for the central parts of cities it is necessary to use network adaptive automated traffic control systems, which use short-term operational forecast of the transport situation. At the same time, most of the existing adaptive automated traffic control systems require a large number of transport detectors at local facilities in the management area.

2. Consideration of stop-lines of crossroads of the network of the management area as a recurrent sequence allowed to analytically determine the value of the intensity of transport flow in the middle of the network according to transport detectors installed on its circuits.

3. The developed empirical-analytical model for determining the intensity of transport flow allows to obtain data on the network of the management area with the number of stop lines over 70 with a given accuracy of $1 \%$ in a short time with the number of iterations not exceeding 15 .

4. Comparison of the results of empirical-analytical modeling of traffic flow parameters with experimental data on 27 networked local objects in the central part of Kharkiv proves that the absolute error of transport flow 
intensity in the directions on the arcs of the network varies in the range of $1-58 \mathrm{vph}$, and the relative error does not exceed $10 \%$. The weighted average network error of 55 hectares does not exceed $3 \%$. The discrepancy of the compared values of intensities is $3,57 \%$, and their variances $-1 \%$, which indicates the adequacy of the model and the possibility of using it for management tasks. The empirical-analytical method allows to calculate the intensity of transport flow at local network facilities up to 300 hectares with a weighted average error not exceeding $10 \%$.

5. During the study of the parameters of dense traffic flows, it was found that at a specific traffic intensity of transport flow in the range of 600-1000 vph the time dynamic dimension of vehicles in the group is subject to a logarithmically normal distribution and is not a constant value. The obtained analytical dependences of the parameters of the logarithmically normal distribution of the time dynamic dimension in a group of vehicles on the specific traffic intensity and the distance from the group-forming object will allow to determine the characteristics of the transport flow movement. It is determined that the level of significance of the obtained approximating models did not exceed 0.05 , the calculated value of the Fisher criterion for all models is larger than the table, which allows to consider the obtained approximating models adequate.

6. The introduction of the empirical-analytical method in the systems of automated traffic control systems will reduce the number of detectors by $46 \%$ in the network of the management area of 55 hectares. Given that the cost of one detector for two lanes in one direction is from 4800 USD (for detector type - inductive frame) up to 7900 USD (for the type of detector - radar), the total cost of the seized detectors in the area of the management area will be $163200-268600$ USD The minimum economy, taking into account the installation of detection systems for the same area is 326400-669120 USD.

\section{References:}

1. Semchenko N.A. (2012). Eksperimental'nye issledovaniya raspredeleniya vremennykh intervalov $\mathrm{v}$ transportnom potoke tsentral'noy chasti megapolisov [Experimental researches of distribution of time intervals in the transport flow of the central part in megacities]. Proceedings of the Transport, ekologiya-ustoychivo razvitie: XVIII nauchno-tekhnicheska konferentsiya s mezhdunarodno uchastie (Bulgaria, Varna, May 10-12, 2012). Varna: TU-Varna, pp. 293-297.

2. Przhibyl P. (2003). Telematika na transporte [Transport telematics]. Moscow: MADI (GTU). (in Russian) 
3. Lobashov O.O. (2010). Modeljuvannja vplyvu merezhi parkuvannja na transportni potoky v mistakh [Modeling the impact of the parking network on traffic flows in cities]. Kharkiv: KhNAMGh. (in Ukrainian)

4. Pen'shin N.V., Pudovkin V.V., Koldashov A.N., Yashchenko A.V. (2006). Organizatsiya i bezopasnost' dvizheniya [Organization and traffic safety]. Tambov: Izd-vo Tamb. gos. tekhn. un-ta. (in Russian)

5. Abramova L.S., Bakulich O.O. (2014). Avtomatyzovani systemy upravlinnja dorozhnim rukhom [Automated traffic control systems]. Kharkiv: KhNADU. (in Ukrainian)

6. Hunt P.B., Robertson D.I., Bretherton R.D., Winton R.I. (1981). SCOOT a traffic-responsive method of coordinating signals. Transport and Road Research Laboratory Report LR 1014, 41 p.

7. Petrov E.A., Vol'f Daniel (2012). Adaptivnaya sistema upravleniya dorozhnym dvizheniem $\mathrm{v}$ sostave gorodskoy ITS [Adaptive traffic management system as part of urban ITS]. Dorozhnaya Derzhava, no. 40, pp. 46-49.

8. Stevanovic A. (2010). Adaptive traffic control systems: domestic and foreign state of practice. Washington, D.C.: Transportation Research Board.

9. Robertson D.I. (1969). TRANSYT: a traffic network study tool. LR 253. Crowthorne, Berkshire: Road Research Laboratory Report.

10. Robertson D.I. (1969). Transyt method for area traffic control. Traffic Eng. Control, vol. 10, pp. 276-281.

11. Sunkari S., Parker R. (2005). Evaluation of Cost-Effective Technologies for Advance Detection. Technical Report 0-5002-1. Texas: Texas Transportation Institute.

12. Karas' Yu.V. (1987). Transportnye potoki $i$ bezopasnost' dvizheniya na avtomobil'nykh dorogakh [Traffic flows and road safety]. Kazan': NKhTI im. S.M. Kirova. (in Russian)

13. Voloshin G.Ya. (ed.) (1981). Rukovodstvo po proektirovaniyu i vnedreniyu avtomatizirovannykh sistem upravleniya dorozhnym dvizheniem na baze ASSUD [Guidelines for the design and implementation of automated traffic control systems based on automated control systems]. Moscow: VNIIBD MVD SSSR. (in Russian)

14. Shatskiy Yu. A. (1970) Metody rascheta rasseleniya v general'nom plane goroda [Methods for calculating settlement in the general plan of the city]. Voprosy gorodskogo transporta. V pomoshch' proektirovshchiku gradostroitelyu, no. 3, pp. 71-84.

15.Efremov I.S., Kobozev V.M., Yudin V.A. (1980). Teoriya gorodskikh passazhirskikh perevozok [The theory of urban passenger transport]. Moscow: Vysshaya shkola. (in Russian)

16. Drew D. (1972). The theory of traffic flow and management. Translated from English. Moscow: Transport. (in Russian)

17. Dmytrychenko M.F. (ed.) (2005). Systemologhija na transporti. Kn. IV: Orghanizacija dorozhnjogho rukhu [Systemology in transport. Book 4: Organization of road traffic Traffic management]. Kyiv: Znannja Ukrajiny. (in Ukrainian)

18. Lazurik V.T., Getsovich E.M., Didenko E.V., Semchenko N.A., Korol' V.Yu. (2011). Razrabotka informatsionnoy sistemy issledovaniya parametrov transportnikh potokov [Development of an information system for studying the parameters of traffic flows]. Proceedings of the Transportnye sistemy megapolisov. Problemy i puti resheniya (Ukraine, Kharkiv, October 11-12, 2011). Kharkiv: KhNU, pp. 15-17. 